Discussion Paper No. 97-30

\title{
Exploring the Tail of Patented Invention Value Distributions
}

Dietmar Harhoff, Frederic M. Scherer, Katrin Vopel 



\section{Non-technical Summary}

Assessing value of patent protection has long been a central issue in the economic literature studying the incentives for innovation in market economies. A number of authors have exploited a particular feature of many (though not all) national patent systems: the renewal fee structure. In many countries, patent holders need to pay annual renewal fees in order to keep patent protection in force. The fees are usually increasing over time in order to weed out less important patents. Using information on the timing of non-renewal, some studies have been able to infer the value of patent protection.

However, these studies cannot use observable information on value differences among those patents that were renewed for the maximum duration of patent protection. But these are presumably the most important patented inventions. Since the valuation distributions are extremely skew, actually observed information in most renewal studies is only available on a small share of the total value of the overall national patent portfolio.

We circumvent this problem by using a novel and more direct approach to the measurement of patent valuation. The paper focuses on the full-term patents of the application year 1977 held by West German and U.S. residents. For the German patents, a two-stage methodology was pursued. A preliminary telephone and telefax screening elicited patent value estimates and identified the most valuable patents, about which on-site interviews were then sought to develop more detailed historical information. For the U.S. patents, only an extended first stage was executed.

Previous studies have found the distribution of patented invention values to be highly skew. We confirm this result, using actual information on the most valuable patents in the 1977 cohort. Several tests were conducted to pin down more precisely the nature of the high-value tail distribution. Three highly skew alternatives were evaluated by graphical and maximum likelihood techniques: the two-parameter log normal, the one-parameter Pareto-Levy, and the three-parameter Singh-Maddala distribution. A two-parameter log normal distribution appears to provide the best fit to our patented invention value data. 


\title{
Exploring the Tail of \\ Patented Invention Value Distributions
}

by

Dietmar Harhoff*, Frederic M. Scherer**, Katrin Vopel*

*Zentrum für Europäische Wirtschaftsforschung (ZEW)

**Harvard University

\begin{abstract}
We explore the tail of patented invention value distributions by using value estimates obtained directly from patent holders. The paper focuses on those full-term German patents of the application year 1977 which were held by West German and U.S. residents. The most valuable patents in our data account for a large fraction of the cumulative value over all observations. Several tests are conducted to pin down more precisely the nature of the high-value tail distribution. Among the Pareto, Singh-Maddala and log normal distributions, the log normal appears to provide the best fit to our patented invention value data.
\end{abstract}

Keywords: Patents, Skew Distributions

JEL Classification: O34, O31

\section{Acknowledgement}

The research underlying this paper was supported by grants from the Sloan Foundation and the ZEW. The authors are also grateful for the invaluable research assistance of Jörg Kukies, Marc Dehoust, Teri Elniski, Renate Häßler, Sascha Karrassek, Stephan Seeberger, Stefan Schmidt, Suzanne Sheldon, and Jesus Viejo Gonzalez, and for helpful comments from Jenny Lanjouw. 


\section{Introduction}

Many industrialized nations charge invention patent holders periodic maintenance or renewal fees. Failure to pay causes the patent permanently to lapse. This phenomenon has been discovered (or rediscovered ${ }^{1}$ ) by economists and exploited to estimate the economic value of patent protection. ${ }^{2}$ The lower the incremental fee at which payment is discontinued, the smaller is the patent right's estimated value. Recent patent renewal studies reveal a highly rightward-skewed distribution of values, with the weight of evidence favoring a log normal distribution of individual patent values, although an even more skew Pareto-Levy distribution has not been ruled out conclusively. However, for the sizeable fraction of patents that remain in force to their full term, the distribution parameters must be derived by extrapolation from patterns for patents allowed to expire earlier. This paper draws upon two new surveys to estimate directly the value of right-hand tail inventions whose patent renewal fees were paid to fullterm expiration.

Exploring the distribution properties of the tail is important, because with skew distributions, outlying tail values account for a large fraction of the cumulative value over all observations. Lanjouw et al. (1996), for example, estimate that within four technology groups, the most valuable five percent of German patents - all presumably renewed to full term - contributed 22 to 31 percent of the total value of all cohort members. The longer and thicker the distribution's right-hand tail, the more difficult it is for business managers to achieve stable average returns through portfolio strategies. Indeed, if the distribution of values is ParetoLevy and the distribution parameter $\alpha<1$, the distribution has neither finite mean nor variance asymptotically, which implies that sample means fail to converge (under the weak law of large numbers) toward a stable value. ${ }^{3}$ Extreme skewness of invention values (as distinguished from the value of covering patents) can also have macroeconomic implications. Assuming a Pareto distribution of high-value

1 For an earlier but less rigorous analysis, see Dernburg and Gharrity (1961-62).

2 See e.g. Pakes and Schankerman (1984), Schankerman and Pakes (1986), Pakes (1986), Lanjouw (1992), and Lanjouw, Pakes and Putnam (1996).

3 See e.g. Johnson et al. (1994), Chapter 20. 
inventions with $\alpha=0.8$, Nordhaus (1989) found through a simulation study that, aggregating across the entire U.S. economy, invention-based productivity effects fluctuated widely over time as a result of unusually favorable or unfavorable Monte Carlo simulation draws. His simulated patterns corresponded remarkably closely to actually observed productivity growth fluctuations.

\section{l. Methodology}

The German patent renewal fee system provided for us a crucial wedge into the full-term patented invention value question. Germany was chosen because its patent examination system is unusually rigorous, screening out applications of low inventive content, and because its renewal fee schedule is one of the most progressive in the world. Figure 1 shows how renewal fees escalated for patents on which applications were filed in 1977. Beginning with DM 100 for the third year, the fees keeping the patent in force over incremental years rose to DM 2,700 for the 18th year. Over the maximum possible term of 18 years, cumulative renewal fees of DM 16,075 had to be paid. ${ }^{4}$

Our survey was targeted toward the Class of 1977 -- i.e., applications with a 1977 German priority date, leading to patents expiring at full term during 1995.5 Since the survey was conducted in 1996, only a year after the final year's fees were paid, memories concerning survey patents' value remained reasonably fresh. Beginning in 1978, inventors seeking patent protection in Germany enjoyed the option of filing patent applications with the European Patent Office. The emergence of two parallel systems complicates the tracking of inventions, and so the Class of 1977 was the last one for which a relatively clean research design could be implemented.

4 The maximum term was extended to 20 years after 1977. For patents declared available for non-exclusive licensing, renewal fees were reduced by 50 percent. Interviews revealed that firms sometimes choose not to pay their fee for the last year because patents are cancelled for non-payment only after half the year has passed.

5 Most of our U.S. sample patents had 1976 U.S. priority dates, but their German counterpart patent expiration dates were geared to 1977 German applications. Some German patents in our sample had application dates (Nachmeldungen) later than 1977, but were entitled to a 1977 German priority. 
The total number of German patent applications filed in 1977 was 57,720, of which 23,998 were from applicants residing in West Germany and the remaining 33,732 from foreign applicants. ${ }^{6}$ The lag from application to issue was bimodal, with mean of 6.5 years, median of 6 years, and modes at three years (16.9 percent of all issues, for unopposed applications) and nine years (11.2 percent of all issues, mostly for applications subject to external opposition after initial publication). Of the 23,834 issued patents, 4,349, or 18.2 percent, were renewed to full term. For the six leading invention-originating nations, the number of patent applications, full-term patents, and full-term renewal rates as a percentage of applications are summarized in Table 1. Full-term renewal rates are considerably higher for foreign patent recipients than for German residents, consistent with the finding of Putnam (1996) that inventors seek patent protection outside their home jurisdictions mainly for their most promising inventions. The extraordinarily high renewal rate for Japan suggests a more aggressive approach to maintaining patent portfolios, see Granstrand (1993).

The research for this paper focused on the full-term patents held by West German and U.S. residents. For the German patents, a two-stage methodology was pursued. A preliminary telephone and telefax screening elicited patent value estimates and identified the most valuable patents, about which on-site interviews were then sought to develop more detailed historical information. For the U.S. patents, only an extended first stage was executed.

Of the 1,435 full-term German patents, it was possible to trace 1,325, or 92.3 percent, to surviving firms or individual inventors. Most of the untraced patent owners were individual inventors or firms too small to be located through standard business directories. The 684 firms or individuals owning the 1,352 traced patents were contacted by telephone to identify the most appropriate respondent, and a questionnaire was dispatched, usually by facsimile, on each relevant patent. Its essence was a single substantive counter-factual question, ${ }^{7}$ translated as follows:

6 Approximately 6,900 of the 57,720 applications were withdrawn by applicants before the 18-month initial publication deadline.

7 On the use of counter-factual questions, see Tetlock and Belkin (1996). 
If in 1980 you had known how its contribution to the future profitability of your enterprise would unfold, what is the minimum price for which you would have sold the patent, assuming that you had a good-faith offer to purchase?

This asset value approach (consistent with the view of patents as intellectual property) was chosen over a question asking for the accumulated flow of profits following pilot interviews with German patent-holders testing both approaches. The team contacting patent owners had a more detailed written protocol answering the most common queries posed by recipients. ${ }^{8}$ Respondents were asked to place their patent within one of five broad minimum selling price ranges: less than DM 100,000, DM 100-399,999, DM 400-999,999, DM 1-5 million, and more than DM 5 million.

Our approach adopts a distinctly different counter-factual assumption than the one implied by previous patent renewal studies. Failure to renew a patent means that the covered subject matter will move into the public domain, allowing it to be used by both the original patent holder and others. Erosion of the original inventor's profits due to non-renewal is often constrained by first-mover advantages shown by Levin et al. (1987) to be more potent on average than patent protection. In our approach, on the other hand, sale of all rights in a patent to a third party implies that the buyer can prevent the original patent holder from practicing the subject invention or demand license fees approaching the value of profits foregone. For broad patents that covered key features of products or processes -- a case found in interviews to be common for the most valuable patents -- the sale of rights puts at risk the whole stream of quasi-rents realizable from a product or process. Or at minimum, the sale of rights can impose upon the seller the profit sacrifice from foregoing key patented features or the cost of inventing around them. Therefore, higher valuations are expected under our approach than under the renewal approach.

8 On the basis of early experience, the question posed in the U.S. survey instrument was altered slightly, conforming to the guidelines used in the German contact team's protocol:

If in 1980 you knew what you now know about the profit history of the invention abstracted here, what is the smallest amount for which you would have been willing to sell this patent to an independent third party, assuming that you had a bona fide offer to purchase and that the buyer would subsequently exercise its full patent rights? 


\section{$\underline{\text { Response Rates }}$}

After extensive follow-up, positive responses were obtained on 772 patents (57.1 percent of the total on which contacts were made) held by 394 organizational entities and individual inventors (including ten unaffiliated inventors). Table 2 reports probit regressions on the characteristics of respondents (unit values) compared to non-respondents (zero values) for 684 full-term patent-holding firms and individuals. Three explanatory variable groups are introduced: firm size (or a dummy variable for independent inventors), industry or (for independent inventors) organizational affiliation, and the professional specialty of the principal contact person. The base (intercept) case is a firm with 50 or fewer employees in the machinery industry, with patent counsel as the principal contact person. The firm size effects are significant and generally rising with employment when they alone are analyzed, but drop to insignificance with respondent and industry effects included. The respondent effects are highly significant, with responses being particularly likely when an inventor or patent attorney was the principal contact. Pseudo- ${ }^{2}$ values reveal that the three sets of characteristics explain at most only modest amounts of response variance.

A separate analysis reported in Harhoff et al. (1997) revealed that the economic valuations elicited in our survey were positively and significantly associated with the number of citations in German patents subsequent to the survey patents. Companies holding four of the most highly cited Class of 1977 full-term patents chose not to participate in the survey. Inspection suggests that those nonresponding patents would have reported relatively high economic values. However, a formal test was unable to reject the hypothesis that citation frequency did not differ between responding and non-responding patents. Thus, there appears to be no strong evidence of selection biases in first-stage survey responses.

The U.S. survey, added as a by-product of the German survey, used a stratified sampling approach. All U.S.-resident holders of two or more full-term German patents (totalling 630) were included in the starting sample, as were 89 holders of a single full-term patent, including 70 patents held by U.S. corporations known to remain in existence and 19 by New England-based individuals and small companies. A manual search of these 719 German patents was conducted to identify U.S. patent application priority serial numbers for the U.S. patent applications on the basis of which, under international rules, a priority filing date is accepted in foreign jurisdictions. From those 719 German patents, 632 could 
be linked to valid U.S. application serial numbers -- sometimes several per patent. Eighty-seven others dropped out because the priority claims were to nations other than the United States (e.g., when the invention came from a foreign subsidiary of a U.S. multinational enterprise) or because no non-German priority claims were reported. The U.S. application serial numbers for the remaining 632 German patents were linked to 485 U.S. patents, which comprised the basis of our U.S. sample. ${ }^{9}$ For the 23 percent of cases with no link to a U.S. patent, the most likely explanation was rejection of applications by the U.S. Patent Office, although there are gaps in the underlying records, and a few parallel U.S. patents may simply have been missed. ${ }^{10}$ For 20 of the 485 U.S. sample patents, no questionnaires were dispatched, in 11 cases because no address could be found for the patent holder and in nine other cases because linking errors were discovered (e.g., the U.S. application was filed too early or too late to support a 1977 German application).

Of the 465 U.S. questionnaires sent, usually after a preliminary telephone contact, 225, or 48.4 percent, were completed by a total of 78 companies or (in three cases) individual inventors. ${ }^{11}$ There was a clear bias in the returns. For 12 companies with eight or more linked patents, the response rate was 37 percent of relevant patents despite intensive follow-up; for firms with fewer than eight patents, the rate was 54 percent, even though follow-ups for the companies with fewer than four patents were less thorough. Two main reasons were given for non-response by the companies with extensive patent holdings: unacceptable compliance burden, and fear that response would reveal too much about the profitability of individual company divisions.

9 The U.S. serial numbers for entities with two or more German patents were linked by the U.S. Patent Office, for which the help of Jane Myers and William Brown is gratefully acknowledged. The link for the single German patent subsample was accomplished using the Boston Public Library's computerized patent data base.

10 Roughly two-thirds of patent applications filed in the United States during the 1970s resulted in issued patents. That only 23 percent of the linked applications failed suggests a positive correlation between the probability of issuance in the two jurisdictions.

11 For some extensively restructured corporations, divisions were treated as separate companies. 


\section{Results}

\section{The First-Stage German Survey}

Table 3 reports the distribution of estimated values for 772 German patents on which first-stage responses were obtained. Ninety-nine patents were valued in the highest range, at more than DM 5 million. Figure 2 plots the cumulative distribution function on doubly logarithmic coordinates. If the distribution of values were Pareto-Levy of the simplest form, it would plot as a straight line on the coordinates chosen, i.e., with $\log \mathrm{N}=\log \mathrm{k}-\alpha \log \mathrm{V}$, where $\mathrm{V}$ is the reported patent value (in thousands of German Marks) and $\mathrm{N}$ is the number of patents with value $\mathrm{V}^{*}$ or greater. An ordinary least squares regression fitted to the data is (with standard deviations in brackets): ${ }^{12}$

$$
\text { (1) } \log \mathrm{N}=3.48-0.385 \log \mathrm{V} ; \quad \mathrm{R}^{2}=0.963, \quad \mathrm{n}=5 \text {. }
$$

Adding a quadratic value term increases $\mathrm{R}^{2}$ by 0.034 , which is significant at the 5 percent level in an F-ratio test. If a log linear regression is fitted to the three highest-value classes (with one residual degree of freedom), the estimated slope is 0.518 . Both slope estimates fall into the range of $\alpha$ values at which Pareto distributions lack asymptotically finite means and variances. Thus, a high degree of skewness is suggested.

In a disaggregated regression over 772 patent responses, the five value reporting classes were characterized by a dependent variable VALUE, ranging from 1 (for the least valuable inventions to 5 (for the most valuable). Zero-one dummy variables were defined for patents originating from electrical industry firms (ELEC, 226 cases), chemical industry firms (CHEM; $\mathrm{n}=131$ ), and machinery makers (MACHY, 203 cases); and for responses from patent counsel (PAT, 426

12 Since we are particularly interested in the right-hand tail of the patent value distribution, we use in this preliminary characterization an unweighted regression of group geometric mean values and ranks, rather than weighting by group patent counts. The slope from observation-weighted maximum likelihood estimate (e.g., in Table 4, Part A) is smaller than the unweighted estimate of regression (1). The lower-bound value for the "less than DM 100,000" group was set at DM 23,000, which approximates the cost of initial patent application plus full-term renewal payments. Logarithms are taken to base ten here. 
cases), research and development executives (RDEXEC, 128 cases), and inventors (INVENT, 77 cases), with all other industries and responses from other occupational specialties serving as the base or intercept case. Other variables were the logarithm of company employment (EMPLOY) and a one-zero dummy GAP for 64 cases with no employment data. The resulting regression, with tratios in brackets, was as follows: 13

$$
\begin{aligned}
& \text { (2) VALUE }=2.49+0.004 \text { ELEC }+0.626 \text { CHEM + 0.200 MACHY } \\
& \begin{aligned}
& {[14.93][0.03] \quad[3.94] } {[1.47] } \\
&- 0.372 \text { PAT }-0.157 \text { RDEXEC + 0.358 INVENT } \\
& {[2.53] \quad[0.95] \quad[1.83] } \\
&+ 0.063 \text { log EMPLOY }-0.010 \mathrm{GAP} ; \\
& {[1.26] } {[0.04] } \\
& \mathrm{R}^{2}=0.0441, \quad \mathrm{n}=772 .
\end{aligned}
\end{aligned}
$$

The value responses of patent counsel are found to be on the conservative side, ceteris paribus, while inventors lean toward relatively generous estimates of their contributions. Chemical industry inventions are more valuable on average by nearly two-thirds of a choice interval, possibily because (as Levin et al. (1987) show) patents provide a particularly strong appropriability regime. The analysis reveals no significant firm size effects. Adding a quadratic employment variable (not separately reported) left both size variables insignificant. Industry, respondent, and company size variables together explain only a small fraction of the variation in patent value responses, suggesting that most of the variation was invention-specific.

\section{The German Interview Survey}

Interviews were sought with all 69 firms owning the 99 patents whose value was estimated at DM 5 million or more in the first-stage questionnaires. Fifty-five onsite interviews were conducted, supplemented by one telephone interview and five cases in which patent holders completed a detailed questionnaire without a face-to-face interview. ${ }^{14}$ The interviews covered a wide range of topics, including

13 Similar results emerged with ordered probit regressions.

14 The interviews were conducted primarily by Jörg Kukies and Katrin Vopel. 
the history of the invention[s] patented, the number of nations in which patents were sought, the extent of licensing (domestic and foreign), the incidence of infringement disputes if any, and most importantly for the present paper, a detailed exploration of the subject patents' value. ${ }^{15}$ Interviewees were asked to supplement the minimum patent rights sale price range answers to the questionnaire's counter-factual question with a point estimate, surrounded when appropriate by a range of uncertainty. In addition, they were asked to estimate the annual sales (including foreign and export sales) and profits, cost savings, and/or royalty receipts attributable to the patented invention, the fraction of profits that would not have been achieved without the patent (usually, the source of the greatest estimation uncertainty), and the role patent protection per se played in sustaining the profits. ${ }^{16}$ Interviewees often had detailed records on which to base their answers because of a German law requiring employers to compensate employee inventors for their inventions using a formula including revenues, profits, the fraction of sales attributable to subject inventions, and the degree of initiative exercised by the employee. ${ }^{17}$ The estimates analyzed here focus in most cases on the profit sacrifice that would have resulted if the firm were precluded from using the patented invention, not on the role patent protection played per se, although in some cases the two questions were disentangled only with difficulty. Some interviews were able to cover in detail only one high-value invention among several held by a respondent. Careful analysis of one (usually the most valuable) was considered preferable to superficial examination of several.

Useable value responses were obtained on 69 patents originally valued at DM 5 million or more. Estimates for ten other patents were considered too unreliable to include in the formal analysis. ${ }^{18}$ Among the 69, profit flow estimates were

15 Other dimensions of the interview responses will be presented in Harhoff et al. (in progress).

16 The questionnaires focused only on German patents. Whether parallel foreign patents were to be included in the counter-factual estimates was left ambiguous. The interviews explicitly tallied the value of both domestic and foreign rights. On average, patents covered by interviews were patented in 10 nations other than Germany, with a standard deviation of 9.9.

17 See Patent- und Musterrecht (1995, pp. 92-109).

18 The estimated average value per patent in those cases was DM 22.6 million. 
available in 54 cases; counter-factual asset sale price estimates were available in 38 cases; and in 23 cases, both flow and asset sale estimates were obtained. In those 23 cases, the geometric mean value was DM 11.1 million per invention with flow estimation and DM 19.1 million in the asset sale counter-factual. Although the differences appear sizeable, they are not significant at the 0.05 level $(\mathrm{t}=1.21)$ in a test of logarithmic means.

The flow value estimates were computed from annual sales and profit ratio data, with all values converted to 1995 price levels and then discounted back to the year 1980 at a 0.05 real discount rate. In what follows, flow value estimates are used in all but the 15 cases in which they were unavailable and counter-factual estimates were substituted. In 57 cases, best estimate values were accompanied by an error range, whose average single-side magnitude was 25.05 percent of the best estimate, with a median value of 22.66 percent.

Thirteen of the best estimates, all based upon flow data, were below DM 5 million. In five of those cases, counter-factual asset value estimates were elicited also at the interview stage. All five were greater than or equal to DM 5 million. Discrepancies resulted in these and other cases for complex reasons - e.g., because a high counter-factual value was placed on the blocking role of patents or on ultimately unrealized but in 1980 plausible option values, because it was difficult to disentangle the role of the invention in a complex systems product or because multiple patents covered the invention, and because respondents estimated surprisingly low profit margins on product sales. We have opted to err on the side of accepting the more conservative flow values when conflicts existed.

Altogether, the best-estimate values ranged from less than DM 1 million (in five cases) to well over DM 1 billion. The mean value was DM 38.8 million if all 69 observations are averaged and DM 15.1 million if the most lucrative invention, with a point estimate roughly 15 times that of the second most valuable invention, is excluded. Figure 3 introduces the values for individual high-value patents into the cumulative distribution function of Figure 2, multiplying each interview patent's rank by 1.45 to reflect the fact that only 69 of the 100 firststage high-value patents yielded usable estimates, and aggregating interview estimates below DM 5 million into appropriate lower-value groups. Relative to Figure 2, the overall distribution becomes considerably more concave downward. The straight-line fit associated with a Pareto distribution is plainly absent. However, the large jump between the largest and second-largest patent value 
leaves considerable uncertainty concerning the distribution's form. If a function linear in the logarithms is forced by ordinary least squares on all 56 observations of DM 5 million or more, the slope is -0.874 , with standard error of 0.033 . If the billion-DM outlier is excluded, the estimated slope steepens to -1.040 , with standard error of 0.027 .

Several tests were conducted to pin down more precisely the nature of the highvalue tail distribution. A graphical test attributable to Bryson (1974) solidly rejected the hypothesis that the distribution for patents valued at DM 5 million or more was negative exponential, Weibull, or any less skew variant. See also D'Agostino and Stephens (1986, Chapter 2).

A difficulty with any test is that our data relate only to the right-hand tail of a wider patented invention value distribution. Figures $4 \mathrm{~A}$ and $4 \mathrm{~B}$ provide a simple graphic test of log normality attributable to D'Agostino (1986, pp. 23-29). Where $\mathrm{V}$ is mean $\log$ patent value and $s$ its standard deviation, we plot the standardized $\log$ normal variate $\mathrm{Z}=\left(\mathrm{V}_{\mathrm{i}}-\mathrm{V}\right) / s$ actually observed against a theoretical $\log$ normal distribution (from published tables) with the same mean and standard deviation. A necessarily arbitrary assumption is that the total number of observations in the high-value half of the theoretical distribution consists of the 69 patents with originally reported values exceeding DM 5 million plus $69 / 100^{\text {ths }}$ of the lower-valued full-term observations. ${ }^{19}$ Thus, the high-value cases with useable point estimates are assumed to be a sample from the hemi-distribution. Not surprisingly, the theoretical log normal variates over-predict the high-value distribution extremity when the single billion-DM outlier is excluded (Figure 4A) and under-predict it when that outlier is included (Figure 4B). For a quantitative comparison with the Pareto-Levy distribution, theoretically predicted values of $\mathrm{V}_{\mathrm{i}}$ were derived from the relationship $\mathrm{V}^{*}{ }_{\mathrm{i}}=\mathrm{V}+s \mathrm{Z}$. The sum of squared deviations SSD between those predictions and the actual $\mathrm{V}_{\mathrm{i}}$ was computed and compared to

19 Because the complete distribution is not known, the means and standard deviations are ambiguous. Where $\mathrm{Z}^{*}$ is the theoretical standardized normal variate derived on the basis of a patent's value rank, best-fitting values were estimated using the transformed regression $\log \mathrm{V}_{\mathrm{i}}=\mathrm{V}+s \mathrm{Z}^{*}{ }_{\mathrm{i}}+\varepsilon_{\mathrm{i}}$, with $\mathrm{V}$ and $s$ as parameters. 
the equivalent SSD from fitting a one-parameter Pareto-Levy regression. ${ }^{20}$ The resulting SSDs (in logarithms to base 10) are as follows:

All patents withV > DM 5 mil.

Largest outlier excluded $(n=55)$

Log Normal
0.6634
0.2345

Pareto-Levy
0.7215
0.3128

In both cases, and especially when the largest outlier is excluded, the fit is better with a $\log$ normal distribution than with the Pareto-Levy.

Maximum likelihood techniques provide a more general approach to the goodness-of-fit problem, permitting inter alia extrapolation of the fitted distribution function to all patents, including those not renewed to full term, and hence excluded from our survey. Three highly skew alternatives were evaluated by maximum likelihood techniques: the two-parameter log normal, the oneparameter Pareto-Levy, and the three-parameter Singh-Maddala distribution. The third of these alternatives, whose high-value tail approximates the Pareto-Levy but does not impose log-linearity on low-value observations, has been used with success in characterizing income distributions. See Singh and Maddala (1976), McDonald (1984), McDonald and Ransom (1979), and Esteban (1986). The likelihood functions used to estimate distribution parameters are summarized in an appendix. Here we focus on the results and their interpretation.

Table 4 summarizes the estimation results and goodness-of-fit tests. Part A focuses only on the patents in our response group, i.e., excluding German-origin patents not renewed to full term and truncating the lower-bound value of the fullterm patents at DM 23,000. ${ }^{21}$ Patents valued above DM 5 million were divided into three discrete groups. Both with and without the most valuable outlier, the

20 For comparability, and unlike regression (3), the sum of squared deviations was minimized in the patent value direction.

21 Estimates for the Singh-Maddala distribution could not be obtained with truncation, since the numerical optimization routine did not converge. For the log normal and Pareto distributions, we experimented with other truncation points, e.g., by analyzing only patents with reported values greater than DM 1 million or DM 5 million. In all cases, the log normal distribution provided a better fit, but the differences between the two became quite small and sensitive to omission of the most valuable patent. 
$\log$ normal form provides a distinctly superior fit. Part B reports maximum likelihood estimates when the distribution includes 9,282 non-renewed Germanorigin patents, assumed to be generally less valuable than the renewed patents but constrained to have positive values. Both with the most valuable outlier included and excluded, the log normal distribution provides by far the best fit, with the Singh-Maddala distribution placing second and the Pareto form third. Chisquared values rise dramatically relative to those for estimates confined to our right-hand tail sample observations, reflecting the larger number of groups and the difficulties of extrapolating outside the range of high-value observations.22 Estimated means and standard deviations for the log normal form also deviate considerably between the truncated and all-patent analyses. ${ }^{23}$ However, graphic inspection reveals that the shape of the right-hand log normal tail changes little between the truncated and all-patent cases. It seems clear that the log normal distribution provides a quite good fit, especially for the high-value tail.

As noted earlier, respondents subjected their best-estimate patent values to a band of uncertainty, often wide, in 57 cases. A sensitivity analysis was conducted to determine how Paretian slope estimates and coefficients of skewness (estimated in the logarithms) were affected by plausible individual patent valuation errors. ${ }^{24}$ Since the error bands were reported as symmetric, random numbers $U_{i}$ distributed uniformly over the unit interval were generated. Letting $\mathrm{V}_{\mathrm{i}}$ be the best-estimate of the $i^{\text {th }}$ patent's value and $D_{i}$ be the reported one-sided error, the Monte Carlo value for that observation was estimated as $V_{i}{ }^{\prime}=V_{i}+\left[\left(U_{i}-0.5\right) \times 2\right] \times D_{i}$. Thus, the average error, half the time negative and half the time positive, was $0.5 \mathrm{D}_{\mathrm{i}}$, with a range from 0 to $\mathrm{D}_{\mathrm{i}}$. The estimated slope values, their standard errors, and skewness coefficients for six Monte Carlo runs, first with all 57 cases with error ranges (including cases with best-estimate values of less than DM 5 million) and then with the billion-DM-plus outlier deleted, are presented in Table 5. The

22 Formally, the Chi-squared values are sufficiently high to reject even the log normal distribution hypothesis, although the power of the test has been questioned. See McDonald (1984) and Kloek and Van Dijk (1978).

23 The parameter estimates here, unlike other parts of the paper, are in logarithms to base e.

24 The coefficient of skewness is computed conventionally as $\mu_{3} / \mu_{2}^{3 / 2}$, where $\mu_{\mathrm{k}}$ is the $\mathrm{k}^{\text {th }}$ distribution moment. Right skewness is indicated by a value greater than zero, left skewness by a value less than zero. 
estimates are fairly insensitive to changes in patent values within the reported range of uncertainty.

\section{The U.S. Survey}

The 485 linked U.S. patents with which our U.S. survey began comprised an even smaller fraction of their applicable universe - less than two percent - than the patents in our German survey. ${ }^{25}$ They were in effect thrice-screened - once by being applied for both at home in the United States and in Germany, once by having applications approved in both relatively stringent jurisdictions, and again by being renewed to full term in Germany. ${ }^{26}$ Because field interviews were not contemplated, the range of values among which respondents were asked to choose was elaborated and expanded to include at the upper bound a category, "more than $\$ 100$ million." Table 6 reports the distribution of outcomes. One respondent placed all three of his company's patents in the "more than $\$ 100$ million" group and added explanatory comments (invited on all questionnaires) showing a clear misinterpretation of the requested counter-factual question. Those three patents are excluded from subsequent analyses, leaving 222 valid responses.

Figure 5 plots the cumulative value distribution on doubly logarithmic coordinates, assuming the minimum value of the least profitable inventions to have been $\$ 40,000$. The ordinary least squares log linear regression equation is given by:

$$
\text { (3) } \log \mathrm{N}=2.945-0.322 \log \mathrm{V} ; \quad \mathrm{R}^{2}=0.976 ; \quad \mathrm{n}=8 \text {. }
$$

25 Inflating for the less than full sampling of entities holding only one full-term German patent, the total number of U.S. counterpart patents must have been approximately 604, or 1.5 percent of the 41,252 U.S. patents issued to U.S. residents in 1978 -- the median year of issue for linked U.S. patents.

26 Among other things, they were cited much more frequently in subsequent U.S. patents. See Harhoff, Narin, Scherer, and Vopel (1997). 
where estimated patent value $\mathrm{V}$ is scaled in thousands of dollars, standard errors are given in parentheses, and logarithms are to the base 10. Modest concavity is evident in the plotted points. When a quadratic value term is added, the 0.022 increase in $\mathrm{R}^{2}$ is significant in an F-ratio test at the 0.01 level. When a linear regression is fitted only to the top four value categories (i.e., \$5 million and higher), the estimated slope is -0.429 , consistent with the tail of a highly skewed Pareto-Levy distribution. However, if that right-hand tail segment is extrapolated, it implies that the single most valuable patented invention would be valued at approximately $\$ 90$ billion. ${ }^{27}$ This is an order of magnitude greater than plausible values associated with the most profitable "blockbuster" drugs, although close to the 1997 stock market value of Microsoft (whose fortunes were based upon multiple innovations, none covered by patents in our sample). It seems probable that within the "more than $\$ 100$ million" open interval, the distribution function must become more concave, as it does within the "more than DM 5 million" interval for the German patent data.

For 48 sample companies with 165 linked full-term patents, it was possible to obtain the 1976 company-financed research and development expenditures which presumably gave rise to the surveyed patented inventions and their estimated value, aggregated to the company level..28 For the closed-end intervals, values were estimated as the geometric mean of the interval bounds. For the open "more than $\$ 100$ million" interval, the average patent value was assumed to be $\$ 250$ million. ${ }^{29}$ This seems a conservative estimate, considering the evidence from our German study that the average value of the most valuable patents was three to seven times the top-value interval's threshold. ${ }^{30}$ Letting VALSUM $_{i}$ be the

27 For the second to fifth most valuable patents, the predicted values are $\$ 17.3$ billion, $\$ 7.3$ billion, $\$ 3.57$ billion, and $\$ 2.12$ billion, respectively.

28 The source of R\&D data was "What 600 Companies Spend for Research," Business Week, June 27, 1977, pp. 62-83.

29 However, in one case, a lower $\$ 100$ million figure was used as a result of additional information provided by the company.

30 Inflating for sample response rates, one might predict from our results approximately 157 inventions valued at more than \$5 million in the United States and 167 inventions valued at more than DM 5 million in Germany. Adjusting for market size differences and 
estimated value of company i's patented inventions and $R \& D_{i}$ its $1976 R \& D$ outlays, the resulting OLS regression for companies with data of acceptable quality was:

(4) $\log$ VALSUM $=-1.174+1.193 \log$ R\&D;

(.55) (.314)

$$
\mathrm{R}^{2}=0.239, \quad \mathrm{n}=48 ;
$$

with logarithms taken to base 10 and standard errors given in parenthesis. The relationship between value and $R \& D$ is positive as expected and highly significant statistically. A ten percent increase in R\&D outlays was accompanied on average by a 12 percent increase in the value of linked patented inventions. There is considerable "noise" in the relationship, however. The standard error of estimate is 1.07 , which means that individual company profits deviated upward or downward by as much as two orders of magnitude from central tendencies implied by the regression equation. Lowering the assumed average value of the above- $\$ 100$ million inventions to $\$ 200$ million reduced the regression coefficient to 1.170 ; the t-ratio remained at 3.80 . In a multiple regression including the logarithm of 1976 company sales along with R\&D outlays, the sales variable had a negative sign, suggesting that larger companies do not realize higher profits from their inventions, ceteris paribus, ${ }^{31}$ but both the sales variable and the increment in $\mathrm{R}^{2}$ fell far short of statistical significance.

For the 48 companies with complete data, company-financed research and development outlays in 1976 totalled $\$ 4.82$ billion, 27.6 percent of the reported $\$ 17.44$ billion aggregate for all of U.S. industry in that year. Assuming an average value of $\$ 250$ million for inventions valued at more than $\$ 100$ million, the total value of those companies' inventions was $\$ 5.16$ billion. That the estimated value of linked full-term renewed inventions, which comprised only a small fraction of all the inventions patented by responding companies, exceeded

purchasing power parity exchange rates, the two most valuable cohort counts do not appear wildly inconsistent.

31 Compare Cohen and Klepper (1996). 
(or at least approximated) total company-financed R\&D outlays suggests that on average the profit rewards to industrial $\mathrm{R} \& \mathrm{D}$ were appreciable. ${ }^{32}$

Going beyond the response limitations of our sample, 1976 R\&D expenditure data were available for a total of 97 U.S. companies with U.S. patents linked to full-term renewed German patents. Those 97 corporations spent $\$ 10.69$ billion on company-financed R\&D in 1976 and obtained approximately 11,087 U.S. patents in 1978, including 381 patents (3.4 percent of their total 1978 patent receipts) linked to full-term German patents. ${ }^{33}$ The OLS regression of all patents received in 1978 by the companies on their R\&D spending, with standard deviations in brackets, was as follows:

(5) $\log$ ALLPATS $=0.570+0.726 \log \mathrm{R} \& \mathrm{D}$; (.107) (.060)

$$
\mathrm{R}^{2}=0.604, \quad \mathrm{n}=97
$$

The more $R \& D$ the companies performed, the more patents they received. However, the relationship between U.S. patents linked to German full-term renewed patents and $R \& D$ exhibits much more noise:

(6) $\log$ LINKPATS $=-0.090+0.298 \log \mathrm{R} \& \mathrm{D}$;

$$
\text { (.112) (.063) }
$$

$$
\mathrm{R}^{2}=0.191, \mathrm{n}=97
$$

Indeed, the relationship is of about the same strength as regression (4), relating (for a sub-sample of companies) the value of linked patented inventions and R\&D.

32 That substantial benefits are realized from unpatented technology and run-of-the-mill patented inventions is shown by Hollander (1965).

33 The total patent counts were derived using the U.S. Patent Office's annual Index of Patents for 1978. Since the counts for subsidiaries receiving patents in other than the parent's name were undoubtedly incomplete, the 11,087 estimate is biased downward. 
We return now to survey data disaggregated to the level of individual linked patents. For most of the patents, information was available on the professional specialty of the questionnaire respondent, the industry from which the invention originated, and the nature of the invention.

Among other things, 202 inventions could be coded as pertaining primarily to a product sold by the company or to a production process used by the company. Of those 202, 27.7 percent were process inventions -- a figure closely comparable to estimates from earlier studies. ${ }^{34}$ Ordering the value responses so that 8 is the highest value category (i.e., for inventions worth more than $\$ 100$ million) and 1 the lowest category (less than $\$ 100,000$ ), the category statistics for product and process inventions were as follows:

\begin{tabular}{lcc} 
& Products & Processes \\
\cline { 2 - 3 } & 3.78 & 3.39 \\
Standard deviation & 2.21 & 1.93
\end{tabular}

There is a hint that process inventions are somewhat less valuable, although the differences are not statistically significant $(t=1.15)$. Being subject to less market risk than product inventions, they may also have less variable values, although the group variances fall just short of significance at the 0.05 level in an F-ratio test.

As with the German data, we test for respondent biases and industry effects. An exact match to the German industry categories was not useful, in part because there were only 10 machinery industry inventions (excluding computers) in the U.S. sample. The U.S. sample composition is better characterized by the following one-zero industry dummy variables: MEDIC (including drugs, apparatus, and surgical supplies) (35 cases); CHEM (excluding drugs) (46 cases); electronics (including computers) ELTRON (57 cases); and scientific and professional instruments (excluding medical and surgical supplies) INSTR (20 cases). The remaining 44 inventions, from a diversity of industries, comprise the intercept case. As with the German data, distinctions are made between questionnaires completed by patent counsel PAT (165 cases), R\&D executives (15 cases), and inventors (only four cases), other categories such as finance staff

34 See e.g. Scherer (1982). 
and top executives entering the intercept. We include also a dummy variable PROCESS with unit value for process inventions. The resulting regression with value groups VALUE varying from 8 to 1 and t-ratios in brackets is:

$$
\begin{aligned}
& \text { (7) VALUE }=3.89-0.686 \text { PROCESS + 0.460 CHEM + 1.271 MEDIC } \\
& \text { [9.97] [2.01] [1.13] [2.95] } \\
& \text { - 0.860 ELTRON - 0.278 INSTR + 0.871 RDEXEC } \\
& \text { [1.91] [0.52] [1.38] } \\
& \text { - 0.966 INVENT - 0.307 PAT; } \\
& \text { [0.90] [0.76] } \\
& \mathrm{R}^{2}=0.142 ; \quad \mathrm{n}=202 .
\end{aligned}
$$

Controlling for industry effects, process inventions are found to be two-thirds of a value group less profitable on average. Drug and surgical supply inventions are significantly more profitable; electronic inventions nearly a category group less profitable. As in the German sample, patent attorneys appear to make relatively conservative estimates, all else equal. Unlike the German results, inventors report relatively less valuable inventions, probably because few of the inventor respondents were employed by companies with a strong commercial orientation.

Patent protection enhances the profitability of intrinsically valuable inventions. To determine whether the strength of patent protection was contributing importantly to our survey results, indices from the so-called "Yale Survey" of the effectiveness of patents in protecting the competitive advantages from product and process inventions in narrowly-defined industries were linked to our patent data, depending upon the line of business in which an invention arose. ${ }^{35}$ Since separate Yale survey indices existed for products and processes, the coding reflected that distinction. To avoid collinearity with the variables used in the Yale coding, the PROCESS dummy was excluded, as were industry-specific dummy variables. Where YALE is the matched Yale survey appropriability index, the resulting regression was:

35 See Levin et al. (1987). The indices varied from 6.88 (in agricultural chemicals) and 6.53 (in pharmaceuticals) down to 2.00 (in electric batteries). Higher values denote greater effectiveness of patents in appropriating the benefits from innovation. 
(8) VALUE $=3.245+0.276$ YALE +0.301 RDEXEC

[4.44] [1.98] [0.47]

+ 0.636 INVENT - 0.991 PAT;

[0.30] [2.49]

$$
\mathrm{R}^{2}=0.080, \quad \mathrm{n}=194 .
$$

Greater effectiveness of patent protection in appropriating the benefits from innovation is found to increase the reported value of our survey inventions, although only by about one-fourth of a value group. Evidently, most of the value differences are specific to the inventions and not the result of generalized patent strength variations. The conservative bias in patent attorneys' responses is shown more strongly than in regression (7).

\section{Implications}

Previous studies have found the distribution of patented invention values to be highly skew. We confirm that conclusion but contribute a new insight: when patent values are measured relative to the counter-factual of being deprived of an invention's use, rather than having the invention lapse into the public domain (as in patent renewal studies), much higher extreme values emerge. Analyzing the renewal of German patents applied for between 1952 and 1972, Ariel Pakes (1986, p. 777) estimated the maximum patent value to be roughly $\$ 420,000$ (in 1980 dollars). Our surveyed maxima are several hundred times greater. Subdividing German patent data into industry groups, Jean Lanjouw (1992, Table 4) estimated an average value per patent for the top 0.1 percent of patents to lie between DM 191,000 and DM 433,000 (at 1975 price levels). Since resident German patent recipients obtained 9,826 patents in 1980, the comparable top 0.1 percent cohort for our sample period includes ten patents. We find the average value of those patented inventions to have been DM 48 million if the most extreme observation is excluded or DM 193 million if it is included -- at least two orders of magnitude larger.

Among several plausible alternative skew distributions, a two-parameter log normal distribution appears to provide the best fit to our patented invention value data. Although the log normal distribution has better-behaved asymptotic properties than the Pareto-Levy alternative, the observed distribution remains 
highly skew. The most valuable five percent of all renewed German patents accounted for 46 to 61 percent of total sample patent value, depending upon whether the largest outlier is excluded or included. In the U.S. sample, the 19 patents valued at more than $\$ 100$ million (8.5 percent of the sample by number) accounted for 76 to 80 percent of total sample value, depending upon whether the average value of those patents is assumed to be 2.0 or 2.5 times the threshold value. The facile convergence to stable means sought in $R \& D$ risk-hedging through portfolio strategies operates at best imperfectly. Investing in technological innovation must be viewed as intrinsically risky, even if (as our U.S. value sums suggest) profitable in the aggregate.

In combination with other evidence on new pharmaceutical compounds and the outcomes of high-technology venture investments (Scherer 1997), we now possess a clear picture of the range of profit or quasi-rent distribution shapes resulting from investments in innovation. Those distributions are the result of stochastic processes played out as the menu of technological possibilities is tapped, market prospects are tested, and competitive forces impinge. Further research will seek to identify likely stochastic processes consistent with the observed profit distributions. 


\section{REFERENCES}

R. B. D’Agostino and M. A. Stephens, Goodness-of-Fit Techniques (New York: Marcel Dekker, 1986).

M. C. Bryson, "Heavy-tailed Distributions: Properties and Test," Technometrics, vol. 16 (1974), pp. 61-68.

W. M. Cohen and S. Klepper, "A Reprise of Size and R\&D," Economic Journal, vol. 106 (July 1996), pp. 925-951.

T. Dernburg and N. Gharrity, "A Statistical Analysis of Patent Renewal Data for Three Countries," Patent, Trademark, and Copyright Journal, vol. 5 (Winter 1961-62), pp. 340-361.

J. M. Esteban, "Income Share Elasticity and the Size Distribution of Income," International Economic Review, vol. 27 (June 1986), pp. 439-444.

O. Granstrand, Profit from Innovation: A Comparison of Swedish and Japanese Intellectual Property Management (Stockholm: Royal Swedish Academy of Engineering Sciences, 1993).

D. Harhoff, F. M. Scherer, and K. Vopel, "Company Patent Policy for Valuable Inventions" (work in progress).

D. Harhoff, F. Narin, F. M. Scherer, and K. Vopel, "Citation Frequency and the Value of Patented Inventions," ZEW Discussion Paper No. 97-27, Zentrum für Europäische Wirtschaftsforschung, Mannheim (1997).

S. Hollander, The Sources of Increased Efficiency: A Study of DuPont Rayon Plants (Cambridge: MIT Press, 1965).

N. L. Johnson, S. Kotz, and N. Balakrishan, Continuous Univariate Distributions (Vol. I; second ed.; New York: Wiley, 1994).

T. Kloek and H. K. Van Dijk, "Efficient Estimation of Income Distribution Parameters," Journal of Econometrics, vol. 8 (August 1978), pp. 61-74.

J. O. Lanjouw, "The Private Value of Patent Rights," Ph. D. dissertation, London School of Economics, 1992.

J. O. Lanjouw, "Patent Protection in the Shadow of Infringement," forthcoming in Review of Economic Studies, 1997.

J. O. Lanjouw, A. Pakes, and J. Putnam, "How To Count Patents and Value Intellectual Property: Uses of Patent Renewal and Application Data," NBER working paper no. 5741, September 1996.

R. C. Levin, A. Klevorick, R. R. Nelson, and S. G. Winter, "Appropriating the Returns from Industrial Research and Development," Brookings Papers on Economic Activity, 1987, no. 3, pp. 783-820. 
J. B. McDonald, "Some Generalized Functions for the Size Distribution of Income," Econometrica, vol. 52 (May 1984), pp. 647-663.

J. B. McDonald and M. R. Ransom, "Functional Forms, Estimation Techniques and the Distribution of Income," Econometrica, Vol. 47 (November 1979), pp. 1513-1525.

W. D. Nordhaus, "Comment," Brookings Papers on Economic Activity: Microeconomics (1989), pp. 320-325.

Patent- und Musterrecht (3rd edition; Munich: Beck-Texte, 1995).

A. Pakes and M. Schankerman, "The Rate of Obsolescence of Patents, Research Gestation Lags, and the Private Rate of Return to Research Resources," in Zvi Griliches, ed., R\&D, Patents, and Productivity (Chicago: University of Chicago Press: 1984), pp. 73-88.

A. Pakes, "Patents as Options: Some Estimates of the Value of Holding European Patent Stocks," Econometrica, vol. 54 (July 1986), pp. 755-784.

J. Putnam, "The Value of International Patent Protection," Ph.D. dissertation, Yale University, 1996.

F. M. Scherer, "Inter-Industry Technology Flows in the United States," Research Policy, vol. 11 (August 1982), pp. 227-245.

F. M. Scherer, "The Size Distribution of Profits from Innovation," forthcoming in: Annales d'Economie et Statistique, special issue 49/50 (January-June 1998).

M. Schankerman and A. Pakes, "Estimates of the Value of Patent Rights in European Countries during the Post-1950 Period," Economic Journal, vol. 97 (December 1986), pp. 1-25.

S. K. Singh and G. S. Maddala, "A Function for Size Distribution of Incomes," Econometrica, vol. 44 (September 1976), pp. 963-970.

P. E. Tetlock and A. Belkin, "Counterfactual Thought Experiments in World Politics," Social Science Research Council Items, vol. 50 (December 1996). 
Table 1: Patent Applications and Full-Term Renewals by Nation, 1977

\begin{tabular}{|l|c|c|c|}
\hline \hline Country of Origin & Applications & Full-Term Patents & Percent Full-Term \\
\hline Germany & 23.998 & 1.435 & 5.98 \\
United States & 9.587 & 896 & 9.35 \\
Japan & 4.289 & 920 & 21.45 \\
France & 2.302 & 215 & 9.34 \\
Switzerland & 2.221 & 205 & 9.23 \\
Great Britain & 2.192 & 165 & 7.53 \\
\hline All Nations & 57.720 & 4.349 & 7.53 \\
\hline \hline
\end{tabular}


Table 2: Probit Analysis of German Patent-Holder Response Behavior*

\begin{tabular}{|c|c|c|c|}
\hline Characteristic & Number of Cases & Firm Size Model & Full Model \\
\hline Individual inventor & 55 & $\begin{array}{l}-0.282 \\
(0.078)\end{array}$ & $\begin{array}{l}-0.441 \\
(0.080)\end{array}$ \\
\hline $\begin{array}{l}\text { Firm Size (employees): } \\
50-249\end{array}$ & 129 & $\begin{array}{c}0.056 \\
(0.061)\end{array}$ & $\begin{array}{c}0.041 \\
(0.066)\end{array}$ \\
\hline $250-499$ & 77 & $\begin{array}{c}0.010 \\
(0.072)\end{array}$ & $\begin{array}{l}-0.010 \\
(0.076)\end{array}$ \\
\hline $500-999$ & 87 & $\begin{array}{c}0.083 \\
(0.066)\end{array}$ & $\begin{array}{c}0.055 \\
(0.074)\end{array}$ \\
\hline 1000-4999 & 112 & $\begin{array}{c}0.192 \\
(0.058)\end{array}$ & $\begin{array}{c}0.104 \\
(0.072)\end{array}$ \\
\hline 5000 or more & 52 & $\begin{array}{c}0.122 \\
(0.075)\end{array}$ & $\begin{array}{l}-0.002 \\
(0.097)\end{array}$ \\
\hline $\begin{array}{l}\text { No. of employees } \\
\text { unknown }\end{array}$ & 57 & $\begin{array}{l}-0.038 \\
(0.080)\end{array}$ & $\begin{array}{l}-0.131 \\
(0.087)\end{array}$ \\
\hline $\begin{array}{l}\text { Cluster } \chi^{2} \\
\text { p-value (df) }\end{array}$ & & $\begin{array}{c}14.4 \\
\mathrm{p}=0.025(6)\end{array}$ & $\begin{array}{c}8.2 \\
\mathrm{p}=0.223(6)\end{array}$ \\
\hline $\begin{array}{l}\text { Respondent Function: } \\
\text { R \& D Executive }\end{array}$ & 142 & & $\begin{array}{l}-0.056 \\
(0.064)\end{array}$ \\
\hline Inventor & 63 & & $\begin{array}{c}0.074 \\
(0.082)\end{array}$ \\
\hline General management & 181 & & $\begin{array}{l}-0.250 \\
(0.061)\end{array}$ \\
\hline Legal counsel & 13 & & $\begin{array}{l}-0.057 \\
(0.155)\end{array}$ \\
\hline Marketing / PR. & 21 & & $\begin{array}{l}-0.371 \\
(0.097)\end{array}$ \\
\hline Function unknown & 30 & & $\begin{array}{l}-0.490 \\
(0.063)\end{array}$ \\
\hline $\begin{array}{l}\text { Respondent Cluster } \chi^{2} \\
\text { p-value (df) } \\
\text { Industry Group } \chi^{2} \\
\text { p-value (df) } \\
\text { Number of observations } \\
\chi^{2}(\mathrm{df}) \\
\text { Pseudo- } \mathrm{R}^{2}\end{array}$ & & $\begin{array}{c}684 \\
38.82(7) \\
0.042\end{array}$ & $\begin{array}{c}51.5 \\
\mathrm{p}=0.001(6) \\
14.6 \\
\mathrm{p}=0.101(9) \\
684 \\
107.2(22) \\
0.116\end{array}$ \\
\hline
\end{tabular}

* Standard errors are reported in parentheses. 
Table 3: Distribution of Full-Term German Patent Value

\begin{tabular}{|l|c|c|}
\hline \hline Estimated Value Range & Number & Percent \\
\hline More than DM 5 million & 99 & $12.8 \%$ \\
DM 1-5 million & 121 & $15.7 \%$ \\
DM 400,000 - 999,999 & 149 & $19.3 \%$ \\
DM 100,000 - 399,999 & 200 & $25.9 \%$ \\
Less than DM 100,000 & 203 & $26.3 \%$ \\
\hline Total & 772 & $100.0 \%$ \\
\hline \hline
\end{tabular}

Table 4: Maximum Likelihood Estimates for Three Alternative Distributions

Table 4.1:Part A: German Patent Survey Responses Only*

\begin{tabular}{|c|c|c|c|c|}
\hline Distribution & Pareto & Pareto & Log Normal & Log Normal \\
\hline Sample & $\mathrm{N}=772$ & $\begin{array}{c}\mathrm{N}=771 \\
\text { Largest Value } \\
\text { excluded }\end{array}$ & $\mathrm{N}=772$ & $\begin{array}{c}\mathrm{N}=771 \\
\text { Largest Value } \\
\text { excluded }\end{array}$ \\
\hline Parameters & $\alpha=0.341$ & $\alpha=0.342$ & $\begin{array}{l}\mu=12.09 \\
\sigma=2.428\end{array}$ & $\begin{array}{l}\mu=12.14 \\
\sigma=2.366\end{array}$ \\
\hline$\chi^{2}(\mathrm{df})$ & $175.3(7)$ & $179.6(6)$ & $22.4(6)$ & $26.0(5)$ \\
\hline
\end{tabular}

* Lower-bound patent value truncation at DM 23.000

Table 4.2: Part B. Including Non-Renewed German-Origin Patents

\begin{tabular}{|c|c|c|c|c|c|c|}
\hline Distribution & Pareto & Pareto & Log Normal & Log Normal & $\begin{array}{l}\text { Singh- } \\
\text { Maddala }\end{array}$ & $\begin{array}{l}\text { Singh- } \\
\text { Maddala }\end{array}$ \\
\hline Sample & $\begin{array}{c}N=772 \\
+9282\end{array}$ & $\begin{array}{c}\mathrm{N}=771 \\
+9282 \\
\text { Largest Value } \\
\text { excluded }\end{array}$ & $\begin{array}{l}\mathrm{N}=772 \\
+9282\end{array}$ & $\begin{array}{c}\mathrm{N}=771 \\
+9282 \\
\text { Largest Value } \\
\text { excluded }\end{array}$ & $\begin{array}{c}\mathrm{N}=772 \\
+9282\end{array}$ & $\begin{array}{c}\mathrm{N}=771 \\
+9282 \\
\text { Largest Value } \\
\text { excluded }\end{array}$ \\
\hline Parameters & $\alpha=0.216$ & $\alpha=0.216$ & $\begin{array}{l}\mu=4.028 \\
\sigma=5.463\end{array}$ & $\begin{array}{l}\mu=4.061 \\
\sigma=5.433\end{array}$ & $\begin{array}{l}a=10.02 \\
b=62.39 \\
q=0.034\end{array}$ & $\begin{array}{l}a=10.19 \\
b=63.83 \\
q=0.037\end{array}$ \\
\hline$\chi^{2}(\mathrm{df})$ & $565.6(9)$ & $573.0(8)$ & $192.7(8)$ & $199.5(7)$ & $325.2(7)$ & $333.5(6)$ \\
\hline
\end{tabular}


Table 5: Sensivity Analysis of Slope and Skewness Parameters

\begin{tabular}{|l|c|c|c|c|c|c|}
\hline \hline & \multicolumn{3}{|c|}{ All 57 Observations } & \multicolumn{3}{c|}{ Extreme Case Deleted } \\
& Slope & $\sigma_{\alpha}$ & Skewness & Slope & $\sigma_{\alpha}$ & Skewness \\
\hline Run 1 & 0.716 & 0.035 & 0.95 & 0.817 & 0.050 & -0.15 \\
Run 2 & 0.702 & 0.036 & 1.00 & 0.812 & 0.052 & -0.24 \\
Run 3 & 0.693 & 0.038 & 1.15 & 0.820 & 0.054 & -0.28 \\
Run 4 & 0.700 & 0.037 & 1.14 & 0.825 & 0.053 & -0.24 \\
Run 5 & 0.694 & 0.037 & 1.19 & 0.824 & 0.053 & -0.24 \\
Run 6 & 0.685 & 0.036 & 0.89 & 0.784 & 0.052 & -0.29 \\
\hline Best estimate & 0.703 & 0.039 & 1.00 & 0.815 & 0.055 & -0.31 \\
\hline \hline
\end{tabular}

Table 6: Distribution of Full-Term U. S. Patent Value

\begin{tabular}{|c|c|c|}
\hline Estimated Value Range & Number & Percent \\
\hline More than $\$ 100$ million & 22 & $9.8 \%$ \\
\hline$\$ 50-100$ million & 6 & $2.7 \%$ \\
\hline$\$ 20-50$ million & 10 & $4.4 \%$ \\
\hline$\$ 5-20$ million & 34 & $15.1 \%$ \\
\hline$\$ 1-5$ million & 41 & $18.2 \%$ \\
\hline$\$ 500,000$ to $\$ 1$ million & 30 & $13.3 \%$ \\
\hline$\$ 100,000$ to $\$ 499,999$ & 45 & $20.0 \%$ \\
\hline Less than $\$ 100,000$ & 37 & $16.4 \%$ \\
\hline Total & 225 & $100.0 \%$ \\
\hline
\end{tabular}


Figure 1

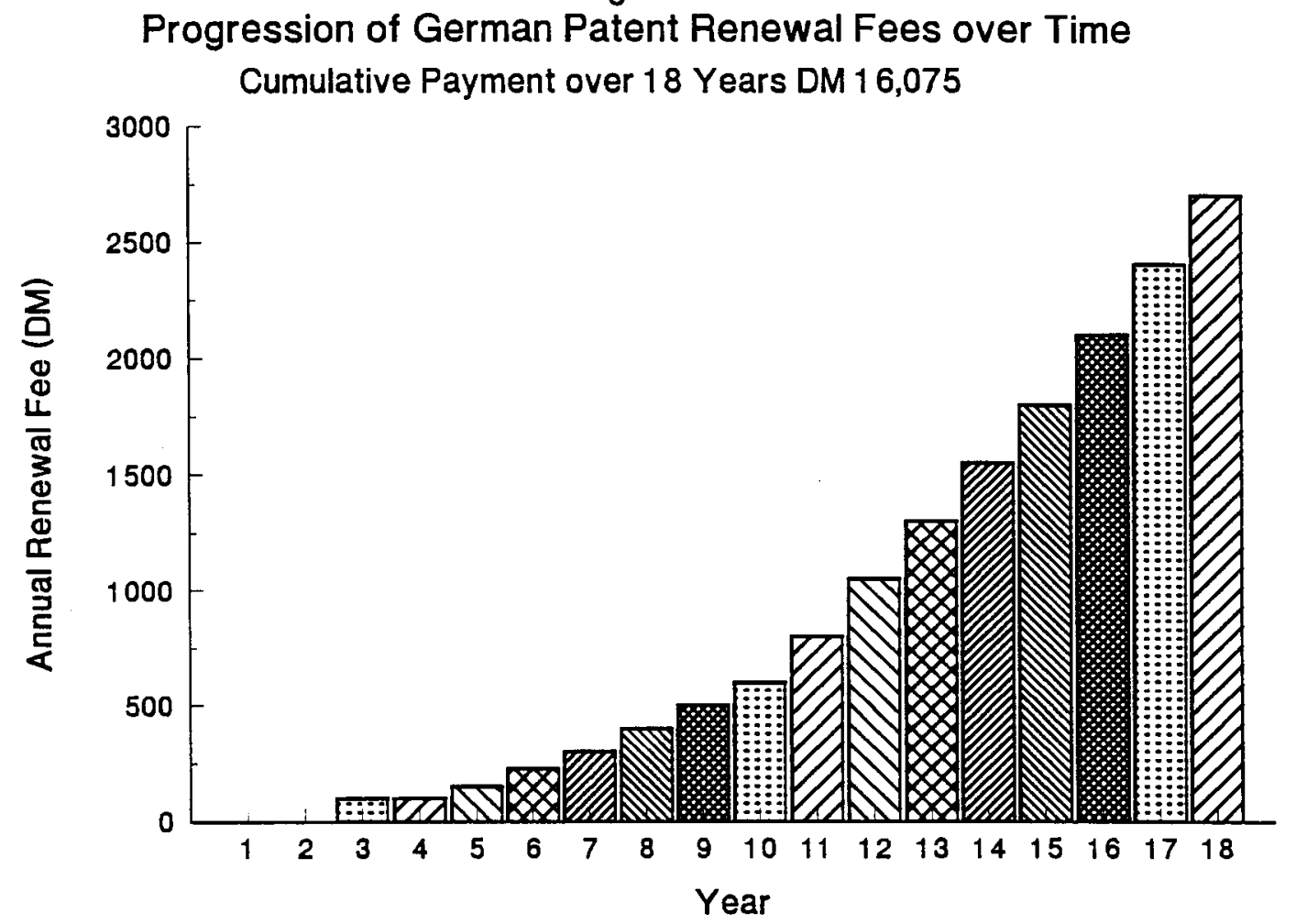

Figure 2

Pareto Plot of Surveyed German Patent Values ( $N=772$ )

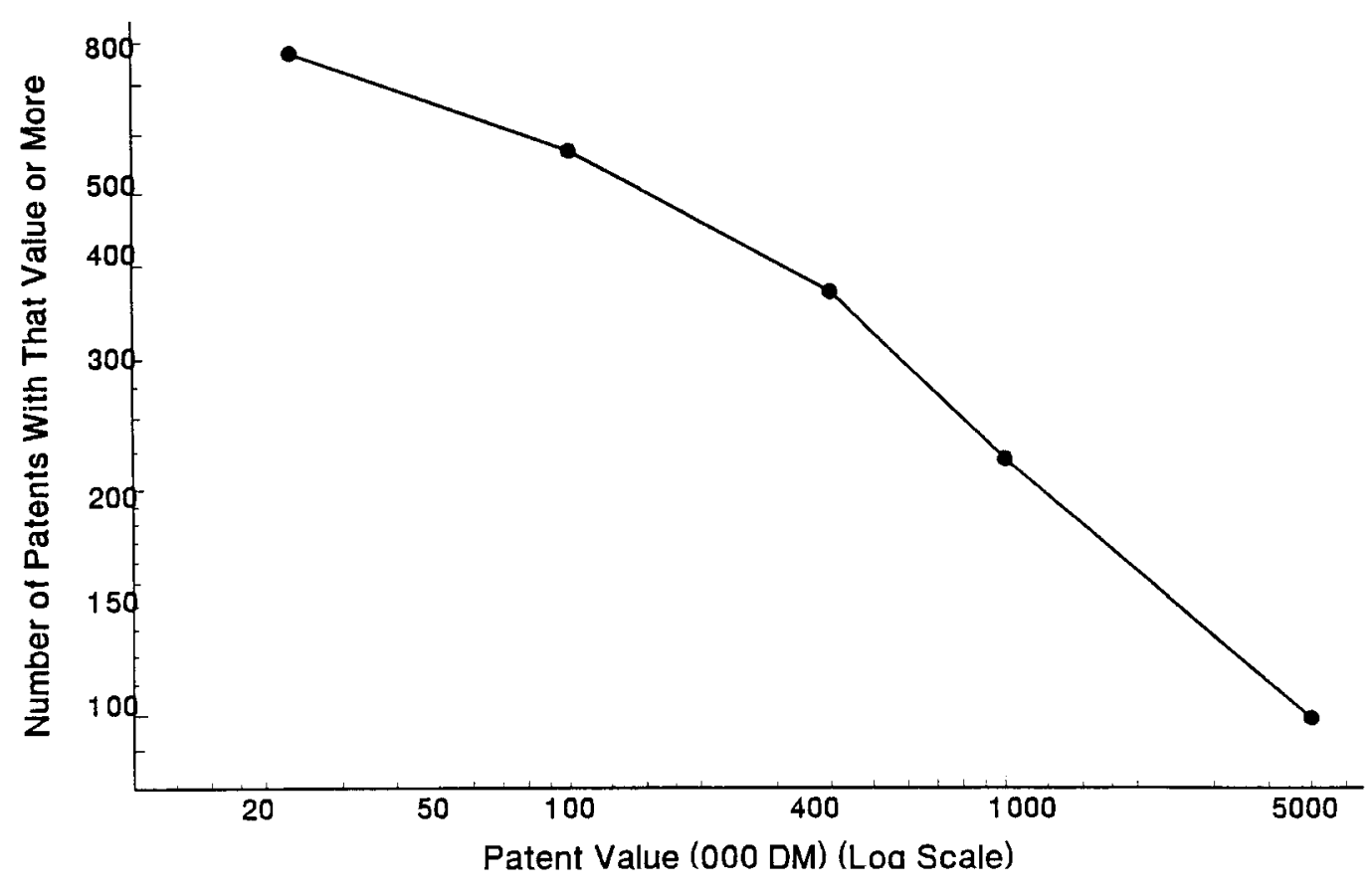


Figure 3

Plot of All Renewed German Patent Values on Pareto Coordinates

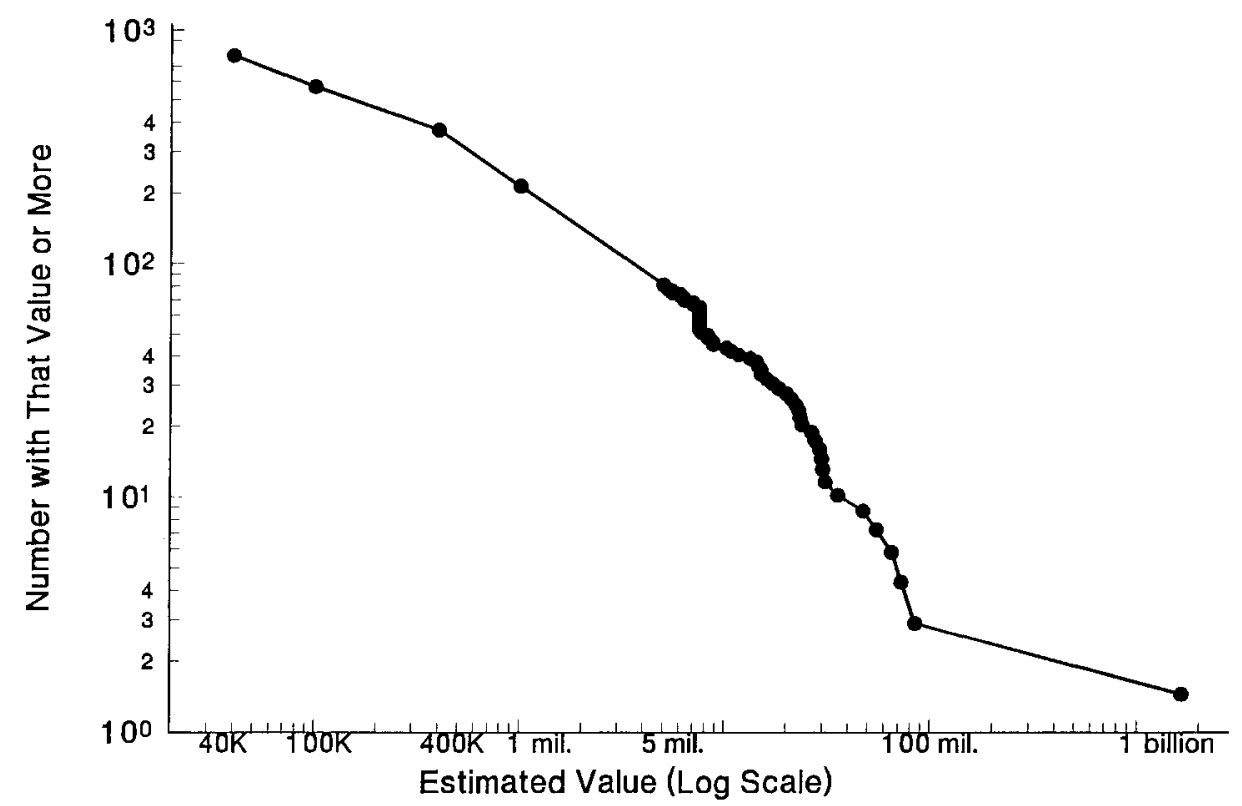

Figure 4A

Log Normal Plot of High-Value German Patent Values

Highest-Value Outlier Excluded; $\mathrm{N}=55$

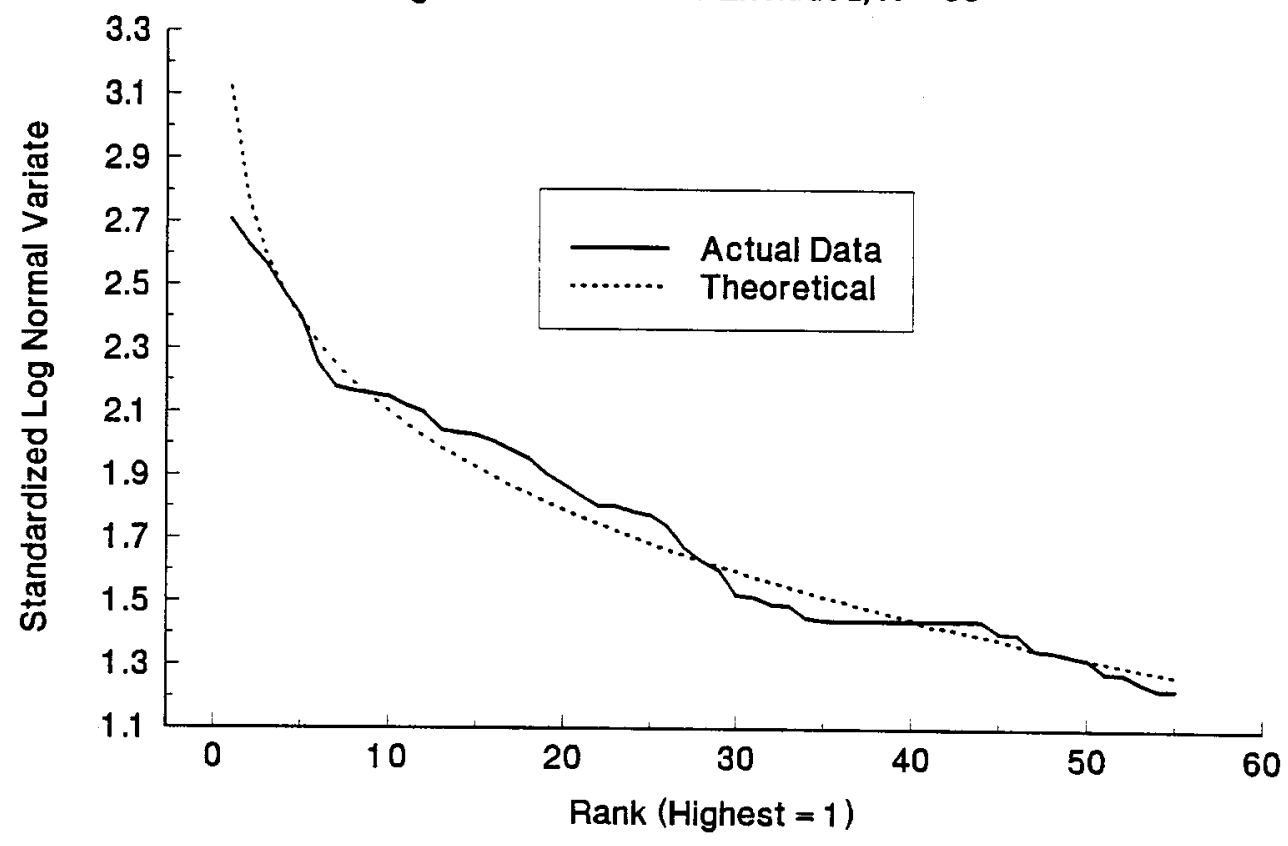


Figure 4B

Log Normal Plot of High-Value German Patent Values

All Patents Valued at DM 5 Million or More

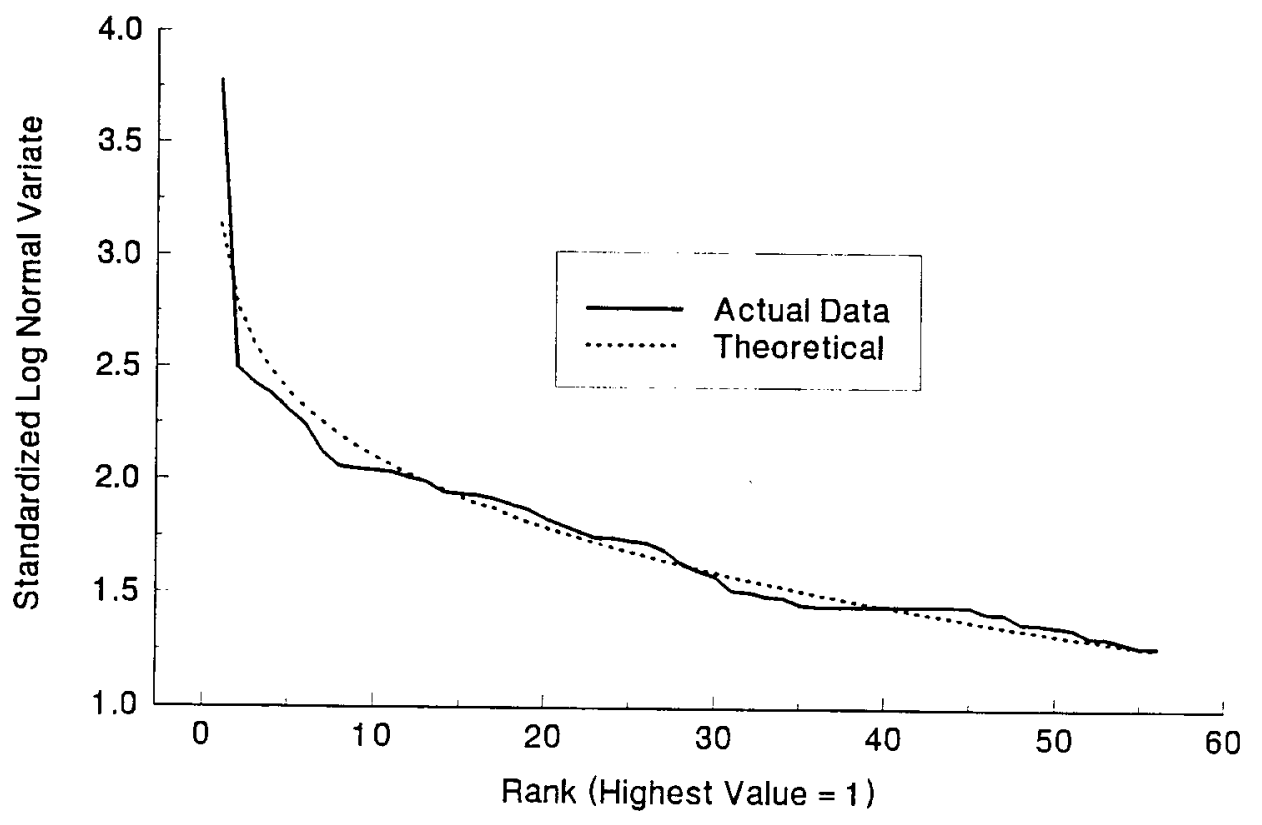

Figure 5

Pareto Plot of U.S. Patent Values $(\mathrm{N}=222)$

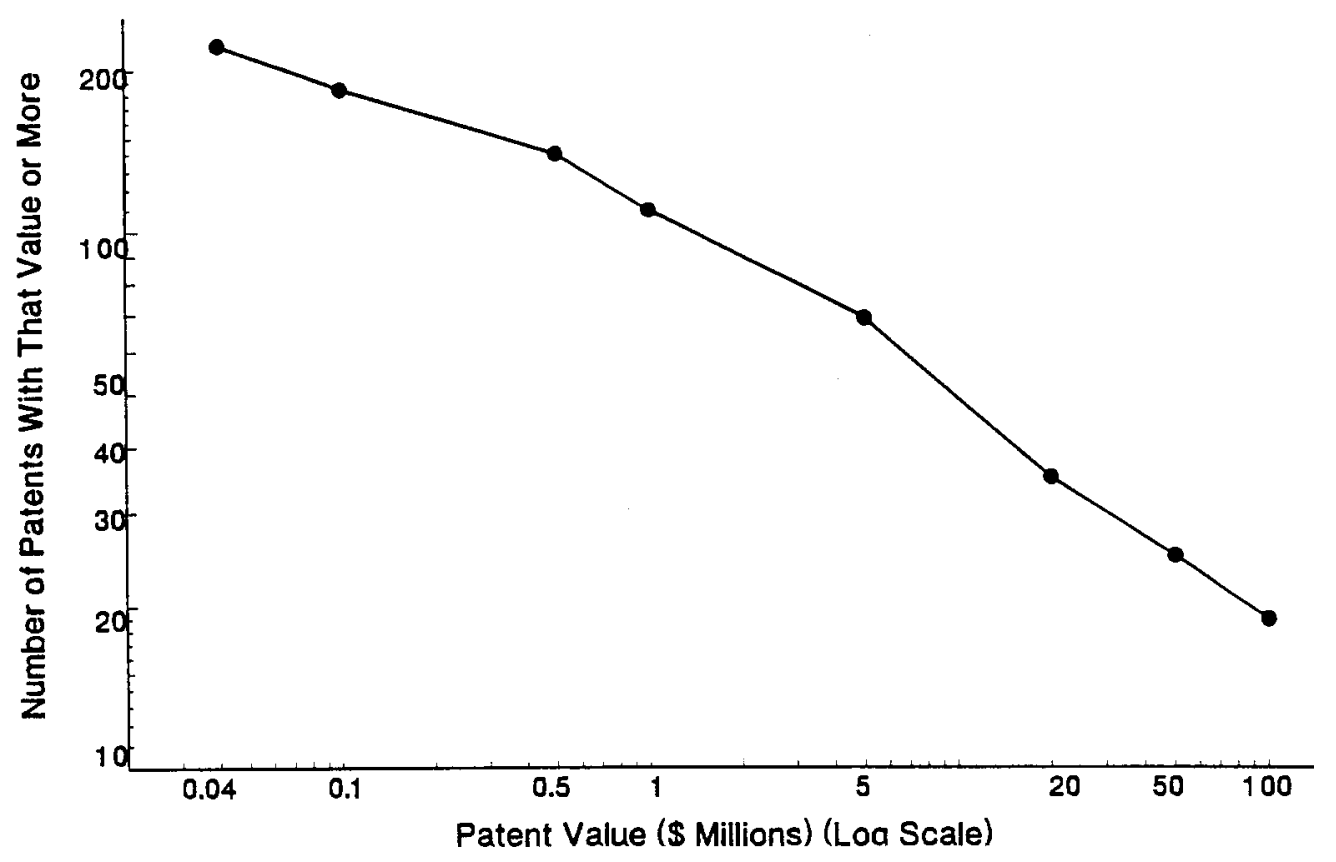




\section{Technical Appendix}

\section{Estimation of Distribution Parameters}

Using the data described in the body of the paper, we estimate the parameters of Pareto-Levy, log-normal and Singh-Maddala distributions. The distribution function for the Pareto-Levy is given by:

$$
\psi(x \mid \alpha)=\left(\frac{X}{X_{0}}\right)^{-\alpha}=x^{-\alpha}
$$

where $x=X / X_{0}$ is defined over the interval $[1, \infty] . X$ is the actual valuation for the patent, and $X_{0}$ corresponds to the minimum valuation for a patent in the sample. The parameter $\alpha$ determines the slope of the distribution function in a $\log$ (value) $-\log$ (rank) plot.

The Singh-Maddala function is a three-parameter distribution with cumulative distributon function

$$
\Sigma(y \mid a, b, q)=1-\frac{1}{\left(1+(y / b)^{a}\right)^{q}} .
$$

where $b$ is a scale parameter and $a$ and $q$ determine the shape of the distribution function.

The third function under consideration is the log-normal whose probability function is given by the standard normal cumulative function evaluated at $(\ln X-\mu) / \sigma$ where $\mu$ is the mean of the $\log$-normal distribution and $\sigma$ is the corresponding standard deviation.

To obtain the estimates in Part A of Table 4, we use the 772 patents for which we obtained valuations in our survey to estimate parameters from truncated distributions. We assume that the value of the patent right is bounded from below at DM 23,000, i.e. the group for which repondents gave a minimum counterfactual sales price of less than DM100,000 is assumed to have values in the interval [23000,100000). The choice of the lower bound is somewhat arbitrary, but approximates the discounted sum of renewal fees in 1995 currency units (in order to be consistent with our patent value estimates).

Each observation enters the likelihood function as the probability of observing a patent right's value to be in a known value interval. The interval observation comes either from the first-stage survey, or it has been obtained in the second- 
stage interviews. In cases where the interviews elicited only a point estimate, we assume that the interval is defined by the point estimate minus respectively plus 10 percent of the point estimate.

Thus, instead of observing the actual values $X_{i}$, we actually observe an upper bound $B_{U i}$ and a lower bound $B_{L i}$ such that $B_{U i} \leq X_{i}<B_{L i}$. Thus, the likelihood function (neglecting constant terms) is given by

$$
\log L(\theta)=\sum_{i=l}^{N_{l}} \log \left(\frac{F\left(B_{U i}, \theta\right)-F\left(B_{L i}, \theta\right)}{1-F(T, \theta)}\right)+\sum_{i=N_{l}+l}^{N_{l}+N_{2}} \log \left(1-\frac{F\left(B_{L i}, \theta\right)}{1-F(T, \theta)}\right)
$$

Here $F($.$) is the cumulative distribution function, \theta$ denotes a vector of parameters, and $T$ is the truncation point, assumed to be equal to DM23,000. The values of observations $\left(1, \ldots, N_{1}\right)$ fall into intervals that are bounded from above and below, while the values of observations $\left(N_{1}+1, \ldots, N_{2}\right)$ are bounded from below, but no upper bound has been established. The latter case occurs whenever we do not obtain detailed interview information on patents with firststage valuations of greater than DM 5 million.

In the case of the Pareto-Levy distribution, the above expression simplifies considerably, since the truncated Pareto-Levy is again a Pareto-Levy distribution. Therefore, the likelihood is given by

$$
\log L(\alpha)=\sum_{i=1}^{N_{1}} \log \left(b_{L i}{ }^{-\alpha}-b_{U i}{ }^{-\alpha}\right)+\sum_{i=N_{1}+1}^{N_{l}+N_{2}} \log \left(b_{L i}{ }^{-\alpha}\right)
$$

where $b_{U i}=B_{U i} / X_{0}$ and $b_{L i}=B_{L i} / X_{0}$ and constant terms are again neglected.

We estimate the parameters by implementing the likelihood function in a nonlinear optimization routine, using Newton-Raphson numerical techniques to obtain numerical solutions. The standard errors are computed from a variancecovariance matrix obtained by multiplication of the score vectors. For each distribution, we perform the estimation with and without the most valuable patent in our sample in order to explore the sensitivity of our results to that particular observation. This is an informal test of robustness, since the estimated parameters of the distribution should not change much if a particular observation is taken from the sample, given that the distributional assumption is correct.

In Part B of Table 4, we take into account that the actual number of Germanowned patents not renewed to full term is actually known. For the Singh- 
Maddala and the log-normal distribution, we assume that patent values are nonzero and positive. The likelihood function is now given by

$$
\log L(\theta)=\sum_{i=1}^{N_{l}} \log \left(F\left(B_{U i}, \theta\right)-F\left(B_{L i}, \theta\right)\right)+\sum_{i=N_{l}+1}^{N_{l}+N_{2}} \log \left(1-F\left(B_{L i}, \theta\right)\right)+\sum_{i=N_{1}+N_{2}+1}^{N} \log \left(F\left(B_{U i}, \theta\right)\right)
$$

where the third group describes the patents that were not renewed to full term in their case, we only know the upper bound of DM 23,000. For estimating the parameters of the Pareto-Levy distribution, we assume that patent values in the latter group range from DM 1 to DM23,000. Note that the lower bound can in principle be estimated, but we have relied so far on the assumptions described here.

For computing a goodness-of-fit measure, we use up to 11 value intervals which are defined by the threshold values DM23000, DM100000, DM400000, DM1 million, DM5 million, DM10 million, DM20 million, DM40 million, DM80 million and DM120 million. The Pearson Chi-Square is computed as

$$
N \sum_{j=1}^{J}\left(\frac{n_{j}}{N}-P_{j}(\hat{\theta})\right)^{2} / P_{j}(\hat{\theta})
$$

where $j$ denotes the interval, $n_{j} / N$ is the actual share of patents observed to be in interval $j$, and $P_{j}(\hat{\theta})$ is the predicted share of observations in the interval. This statistic is distributed as a Chi-Squared random variable with $J-k-1$ degrees of freedom, where $k$ is the number of distribution parameters estimated. 